Disponível em:

http://editora.unoesc.edu.br/index.php/race

Race, Joaçaba, v. 15, n. 2, p. 601-620, maio/ago. 2016

\title{
EFEITO MANADA NO MERCADO DE CAPITAIS: UM ESTUDO COM GERENTES DE BANCOS PÚBLICOS DO DISTRITO FEDERAL
}

Herd effect in capital markets: a study with managers in public banks of the Federal District

Luiz Medeiros de Araujo Neto

E-mail: medeiros2002@hotmail.com

Especialista em Finanças pelo Instituto Alfa; mestrando em Administração pela Universidade de Brasília.

Andre Luiz Marques Serrano

E-mail: andrelms@unb.br

Doutor em Economia pela Universidade de Brasília; Mestre em Economia Aplicada pela Universidade de Brasília; Professor Adjunto de Economia na Universidade de Brasília. Endereço para contato: Campus Universitário Darcy Ribeiro, 70910-900, Brasília, Distrito Federal, Brasil.

\section{José Carneiro da Cunha Oliveira Neto}

E-mail: joseccon@gmail.com Doutor em Administração pela Universidade de Brasília; Mestre em Economia pela Universidade Católica de Brasília.

Roberto Lúcio Corrêa de Freitas

E-mail: rlcfreitas39@gmail.com Mestre em Administração pela Universidade de Brasília; Especialista em MBA Executivo em Negócios pela Universidade Norte do Paraná; Professor do Instituto Federal de Educação, Ciência e Tecnologia do Norte de Minas Gerais.

Emmanuel Sousa de Abreu

E-mail: emmanuelsabreu@gmail.com

Mestre em Ciências Contábeis pela Universidade Federal da Bahia; doutorando em Finanças e Métodos Quantitativos pela Universidade de Brasília.

Artigo recebido em 03 de março de 2016. Aceito em 19 de abril de 2016. 


\section{Resumo}

O objetivo com este trabalho foi verificar se os gerentes de bancos estatais, autorizados a recomendar investimentos, sofrem influência de opiniões externas em decisões de aquisição de ativos financeiros. A pesquisa se justifica em razão da necessidade de se saber se mesmo agentes com elevado conhecimento em finanças e acesso à informação poderiam sofrer influência da opinião emitida por analistas de mercado no momento da decisão de compra desses ativos. Para tal, foram aplicados 80 questionários a gerentes autorizados a recomendar investimentos, em três bancos públicos localizados no Distrito Federal. Para a operacionalização estatística, foram utilizados testes de hipóteses para se verificar se existiam diferenças significativas entre a escolha de gerentes sob influência externa e de outros sem essa interferência. Concluiu-se que a opinião do analista não influencia a forma de qualificar as ações da empresa, porém foram achadas fortes relações entre a opção de compra e a opinião do analista.

Palavras-chave: Finanças comportamentais. Efeito manada. Assimetria de informação.

\section{Abstract}

The aim with this paper was to investigate if managers of state banks, authorized to recommend investments, are influenced by external opinions on acquisition of financial assets. The research is justified by the need to know if market agents with extensive knowledge in finance and access to information could be influenced by the opinion issued by market analysts. Eighty questionnaires were applied to managers who were authorized to recommend investment in three state-owned banks located in the Federal District. Statistical tests were used to check whether there were significant differences between the choice of managers under external influence and others without this interference. It was concluded that the opinion of the analysts do not influence the way of qualifying the company's shares, but was found strong relationships between the acquisition option and the analysts'opinions were found.

Keywords: Behavioral finance. Herd behavior. Asymmetric information.

\section{INTRODUÇÃO}

A teoria clássica de finanças se baseia, principalmente, nos pressupostos da microeconomia neoclássica. Um desses pressupostos mais clássicos é que os agentes são maximizadores de utilidade, com racionalidade ilimitada (preferências completas e transitivas), sendo, assim, capazes de selecionar a melhor cesta ao seu alcance, ajustando o risco pelo retorno esperado (MARKOWITZ, 1952; YOSHINAGA et al., 2008). Apesar de essas pressuposições serem difíceis de ser observadas no mundo real, são elas que fundamentam os modelos do mainstream na área. 
Indo de encontro a esses pressupostos clássicos em finanças, as teorias de finanças comportamentais acreditam que os agentes de mercado podem se comportar de maneira sistematicamente irracional, impactando consistentemente o mercado de capitais (KIMURA, 2003). As finanças comportamentais vêm encontrando evidências de que agentes violam axiomas como o da transitividade, atribuindo pouca importância para a lei dos grandes números e para informações relevantes, e, de forma sistemática, supervalorizam informações sem relevância, acreditando fielmente em previsões para eventos incertos (CONLISK, 1996).

Dessa forma, os estudos na área de finanças comportamentais versam sobre os erros nos modelos tradicionais descritivos de finanças referentes às hipóteses de comportamentos cognitivos dos agentes. As pesquisas avançaram incorporando temas como psicologia e economia com o intuito de esclarecerem o processo de decisão no ambiente financeiro.

Alguns desses erros podem ser observados em situações nas quais os agentes são influenciados em sua tomada de decisão pelo que outros ao seu redor decidiram, ou pelo que o agente crê que eles esperam. É fácil verificar esse tipo de comportamento em eventos cotidianos como a escolha de lojas, restaurantes, escolas ou marcas com base em quão populares são. Keynes (1936) diz que essa é também a forma como os investidores nos mercados de ativos, muitas vezes, comportam-se, fenômeno conhecido em finanças comportamentais como "efeito manada”.

Considerando-se que o comportamento humano em decisões financeiras sob incerteza é fundamental para se avaliarem os funcionamentos dos mercados, questionou-se: as decisões de gerentes de bancos estatais sobre aquisição de ativos se aproximam de escolhas com racionalidade ótima, como preconiza a teoria clássica de finanças, ou essas decisões sofrem influência de opiniões externas em razão do efeito manada descrito pela teoria comportamental de finanças?

Nesse caminho, neste artigo levanta-se a hipótese de que as decisões dos gerentes de conta sob influência externa são significativamente diferentes das decisões sem tal influência, o que refutaria a hipótese de racionalidade adotada pela teoria clássica em finanças, mesmo quando testada em agentes com formação adequada e acesso à informação. Assim, para o atual estudo foram escolhidos como objeto de estudo os gerentes de bancos autorizados a recomendar investimentos, mais especificamente, os que atuam em bancos públicos. Partiu-se da ideia de que esses profissionais, em virtude de sua qualificação e atividade, sejam menos suscetíveis ao efeito manada, representando, assim, uma boa proxy conservadora de agente racional. 
Em suma, neste trabalho questiona-se se a opinião de analistas poderia influenciar a forma como pessoas com alto grau de conhecimento em finanças avaliam um ativo, e, ainda, se a opinião daqueles influenciaria a opção de compra deste. O objetivo, então, é testar pressupostos clássicos empiricamente, tendo como embasamento teórico os conhecimentos em finanças comportamentais. Mais precisamente, verificar se gerentes de bancos públicos que estão autorizados a recomendar investimentos sofreriam influência de analistas na eventual compra de ações.

O presente artigo está estruturado em cinco seções, incluindo esta introdução. Na segunda seção é apresentada uma breve revisão relativa à teoria dos prospectos e à teoria clássica em finanças, as quais respaldam as duas hipóteses de pesquisa. Na terceira seção é apresentada a metodologia aplicada à pesquisa, como teste de normalidade e de qui-quadrado para se verificar se existe a influência do analista na opção de compra entre os entrevistados, além do teste Mann-Whitney para se verificar se há relevância estatística na maneira como os dois grupos avaliam a empresa. $\mathrm{Na}$ quarta seção, apresenta-se a análise dos resultados obtidos, na qual se constata que há influência do analista na opção de compra, mas não é possível confirmar uma diferença significativa na forma de avaliação de uma empresa. Finalmente, na quinta seção, expõem-se os pontos conclusivos e sugestões para pesquisas futuras.

\section{TEORIA CLÁSSICA E RACIONALIDADE ILIMITADA}

Como já brevemente comentado, a teoria clássica de finanças possui um caráter fortemente normativo por estabelecer pressupostos baseados em um “dever-ser” ótimo, principalmente por se fundamentar na teoria microeconômica neoclássica. Entre estes, podem-se elencar as expectativas racionais e a utilidade esperada. Pressupor esses dois pilares indica um tratamento de agentes racionais capazes de avaliar todas as opções (preferências completas) e ordená-las perfeitamente (preferências transitivas).

Nesse caminho, Neumann e Morgenstern (1944) lançaram as bases para a modelagem matemática do comportamento humano utilizado tradicionalmente, o qual ficou conhecido como a Teoria da Utilidade Esperada. Em seu modelo, as pessoas seriam agentes maximizadores de utilidade esperada, dadas as restrições sob a forma de axiomas. Dessa forma, ao se verificar aderência aos axiomas, seria possível construir uma função utilidade que representasse as preferências de um indivíduo. A indexação cardinal oferecida pela função de utilidade, de Neumann e Morgenstern (1944) é compatível com a interpretação operacional de utilidade como no caso sem incerteza. Já quando adicionado à incerteza isso não é verificado, visto que trans- 
formações monotônicas podem não preservar a forma da função utilidade esperada. Com isso, a preservação somente seria garantida por meio de transformações lineares crescentes, limitando bastante a capacidade preditiva do método (CUSINATO, 2003).

A título de exemplo, é a partir desses preceitos que se postula a hipótese de eficiência de mercado (HME), originada dos estudos de Bachalier (1900) e Cowles (1903). Já por meio da literatura em Economia Financeira, as pesquisas se iniciam pelos manuscritos de Samuelson (1965) e Fama (1970) (CAMPBELL; LO; MACKINLAY, 2012). Samuelson (1965) acredita que em um mercado eficiente a previsibilidade do preço dos ativos não seria possível, já que todas as informações que afetam o preço do ativo estariam disponíveis aos agentes. Para Fama (1970), o mercado de capitais seria eficiente se os preços dos ativos refletissem todas as informações relevantes e disponíveis. Dessa forma, segundo a HME, a eficiência no mercado de capitais poderia ser subdividida em três níveis, a saber: fraco, semi-forte e forte (ODA; YOSHINAGA; FAMÁ, 2005).

a) forma fraca: estabelece que o conjunto de informação disponível inclui apenas o histórico dos preços ou retornos dos ativos que integram o mercado;

b) forma semi-forte: nela, o conjunto informacional disponível inclui todas as informações públicas disponíveis;

c) forma forte: o valor do título reflete todo o conjunto informacional, que nessa classe se refere a todas as informações relevantes, públicas e privadas.

Havendo eficiência informacional no mercado, todas as informações relevantes sobre os ativos estariam disponíveis e já incorporadas ao preço (FARHI, 1999). Caso haja mau apreçamento de um ativo, seria, então, possível fazer operações de arbitragem, as quais trariam o ativo a seu valor real (THALER; BARBERIS, 2003). No entanto, as teorias comportamentais acreditam que qualquer estratégia, adotada no mudo real, não poderia ser chamada de arbitragem, visto que incorreriam em incerteza. A partir desse preceito, os preços dos ativos poderiam permanecer equivocados (SHLEIFER, 2000).

\section{TEORIA DO PROSPECTO E EFEITO MANADA}

As finanças comportamentais se originam como uma área de estudo no fim do século XX a partir dos estudos de Kahneman e Tversky (1974, 1979), em que se originou o corpo teórico intitulado Teoria do Prospecto (ARRUDA, 2006). Para isso, foram utilizadas teorias em psicologia, economia e finanças para tentar compreender 
de forma mais realista os mercados de capitais e o comportamento de seus agentes (CARMO, 2005). Considerando-se que a obtenção de informação está associada a um custo, seja ele de aquisição, seja de pesquisa, esse custo por si só já geraria uma assimetria de informação que deve culminar em ineficiência de mercado. Em 1972, as pesquisas comportamentais de Slovic, as quais versaram sobre problemas na percepção do risco, abriram caminho para o estudo da influência de aspectos psicológicos no processo de tomada de decisão dos investidores (KIMURA, 2003).

Cabe destacar que Simon (1978) desenvolveu uma teoria de racionalidade limitada na qual propõe que a capacidade das pessoas em lidar com as informações necessárias para a tomada de decisão é limitada, e que a emoção contribui para que isso não aconteça (BARBEDO; SILVA, 2008). Posteriormente, Kahneman e Tversky (1979) constataram que o comportamento humano, ainda que irracional, pode não ser imprevisível, sugerindo que diversas irracionalidades são sistemáticas. As pesquisas desenvolvidas na área mostram sinais de ineficiência no mercado de ações, apontando para possíveis ganhos com tais imperfeições de mercado. As pessoas seriam incapazes de tomar decisões completas quando houvesse algum grau de incerteza no futuro (CARDOSO; RICCIO; LOPES, 2008).

A cognição é a forma na qual os impulsos sensoriais são transformados, elaborados, armazenados, reduzidos, utilizados e recuperados (TVEDE, 2000; SHLEIFER, 2000). É por meio de processos cognitivos que os seres humanos elaboram suas decisões, as quais implicam o uso de heurísticas, úteis para o processo decisório, mas que, como consequência, pode levar os agentes a incoerências ou a erros sistemáticos. Haveria, então, a possibilidade de reversões de preferências entre as alternativas de escolhas ao modificar-se a apresentação do problema; Kahneman e Tversky (1981) chamaram esse fenômeno de Efeito Framing. Para Araujo Neto e Freire (2013), os processos cognitivos seriam considerados recursos escassos para a decisão, podendo ser sujeitos a vieses. Muitas decisões são baseadas em crenças, fazendo com que incorram em incerteza. Esses eventos em incerteza poderiam, por meio de proxies, ser expressos de forma numérica como probabilidade ou probabilidade subjetiva, no entanto, os vieses de heurística podem levar a um resultado equivocado (KAHNEMAN; TVERSKY, 1974).

Assim, como alternativa à Teoria da Utilidade Esperada, Kahneman e Tversky (1979) propõem uma nova maneira de descrever e pensar o processo decisório de agentes sob incerteza. Para os autores, as escolhas entre as perspectivas de incerteza apresentam vários efeitos que são inconsistentes com os princípios básicos da teoria da utilidade. Em particular, as pessoas atribuiriam um peso inferior para resultados 
que são apenas prováveis em comparação aos resultados que são obtidos com certeza (KAHNEMAN; TVERSKY, 1979). Essa tendência, o chamado efeito de certeza, contribuiria para a aversão ao risco nas escolhas envolvendo certeza de ganhos ou de exposição ao risco. Segundo Kahneman e Tversky (1979), as pessoas em geral descartam componentes compartilhados por todas as perspectivas em questão. Essa tendência, o chamado efeito de isolamento, leva a preferências inconsistentes quando a mesma alternativa é apresentada de formas diferentes.

Na Teoria dos Prospectos, as alternativas de escolha são desenvolvidas de forma que o valor seja atribuído a ganhos e perdas em vez de bens finais, e em que as probabilidades são substituídas por pesos de decisão (KAHNEMAN; TVERSKY, 1979). Como resultado, a função de valor é, normalmente, côncava para ganhos (possibilidade de maximização) e comumente convexa para perdas (possibilidade de minimização). No entanto, ao contrário da Teoria da Utilidade Esperada, na Teoria dos Prospectos a função é mais íngreme para perdas do que para ganhos (KAHNEMAN; TVERSKY, 1979).

Essas heurísticas não são incorretas, na verdade, o uso delas é essencial para a tomada de decisão dos seres humanos sob incerteza. Podem, também, ser a manifestação de experiências acumuladas em determinadas atividades. O problema reside nos vieses causados pelas heurísticas, que provocariam desvios sistemáticos da resposta ótima.

Em finanças comportamentais, o efeito manada descreve como investidores podem tomar decisão sem uma orientação planejada. Já na teoria tradicional de finanças, a expressão efeito manada pode ser definida como o comportamento correlacionado entre investidores (BIKHCHANDANI; SHARMA, 2001). Esse comportamento seria observado quando um grupo de investidores imitasse o comportamento de outro, ignorando suas próprias análises e percepções do mercado (SANCHES, 2013). Existem diversos motivos que podem justificar teoricamente que um indivíduo altere suas decisões de investimento a partir do momento que tome conhecimento do comportamento de outros (LAKONISHOK; SHLEIFE; VISHNY, 1992; CHRISTIE; HUANG, 1995; SIAS, 2004). Um deles é que o comportamento do grupo indica a existência de informações adicionais sobre o mercado, e, assim, o comportamento de manada ocorreria por uma presunção de informação complementar pelo mercado. Por outro lado, existem explicações que indicam que o ser humano, por essência, teria uma preferência por conformidade, e, logo, o efeito manada ocorreria em consequência dessa busca por padrões de diagnóstico e decisão.

Adicionalmente, existem estudos especialmente direcionados para averiguar o comportamento de gestores de recursos (LAKONISHOK; SHLEIFE; VISHNY, 
1992; SIAS, 2004; CHIANG; ZHENG, 2010). Uma explicação para o comportamento singular desses agentes se justificaria pelo fato de estes, muitas vezes, terem suas performances avaliadas por comparação à performance de mercado. Assim, os gestores não teriam como objetivo a maximização do resultado com minimização do risco, mas, sim, uma busca de resultados em conformidade com os retornos de mercado, gerando-se uma avaliação satisfatória do seu próprio desempenho. Essa ideia é especialmente importante para o presente trabalho, pois é uma das possíveis explicações para o comportamento dos gerentes bancários que recomendam investimentos. Evidências dessas ideias teóricas serão vistas na próxima seção.

\section{EVIDÊNCIAS DO EFEITO MANADA NO MERCADO FINANCEIRO}

Estudos que discutem a influência do efeito manada utilizando a abordagem da teoria comportamental ainda são relativamente recentes, contudo, existem na literatura alguns estudos que evidenciam a existência desse comportamento.

Trueman (1994) estudou o efeito manada pela ótica do analista. Os seus achados evidenciam que as previsões produzidas não refletem as informações disponíveis de forma imparcial. Como consequência, há o surgimento de um comportamento de manutenção do status quo, ou seja, de produzir projeções a partir de resultados passados, ainda que essas previsões fujam do que seria esperado considerando-se as informações atuais.

Já Lakonishok, Shleifer e Vishny (1992) investigaram o efeito manada no mercado de ações por meio dos ativos detidos por 769 fundos americanos, em sua maioria fundos de pensão, de 341 gestores entre 1985 e 1989. Os fundos são compostos com uma periodicidade quadrimestral. Não foram verificadas evidências significativas de efeito manada no comportamento desses gestores. Quanto ao tamanho das ações, ou seja, a capitalização, eles encontraram uma evidência fraca de efeito manada em títulos de menor capitalização (small cap).

Lobão e Serra (2002) analisaram 32 fundos que operaram em Portugal entre 1998 e 2000. Seus achados sugerem um nível de efeito manada mais elevado em mercados emergentes do que o encontrado em mercados maduros.

Especificamente, no Brasil, Kutchukian, Eid Junior e Dana (2010) encontraram evidências de efeito manada em diferentes grupos de investidores, separados de acordo com o porte de seu investimento, por intermédio de um método baseado na direção das captações líquidas de um grande número de fundos de investimento: ações, renda fixa e multimercado. 


\section{PROCEDIMENTOS METODOLÓGICOS}

Para a execução dos objetivos propostos, realizou-se uma pesquisa de campo mediante a aplicação de um questionário. A população-alvo do estudo foram os gerentes de bancos públicos do Distrito Federal com autorização para recomendar investimentos. Para tanto, foi constituída uma amostra com gerentes de três bancos públicos, todos com autorização para recomendar investimentos e localizados no Distrito Federal, a saber, Banco do Brasil, Banco Regional de Brasília e Caixa Econômica Federal.

A escolha de bancos estatais para composição da amostra buscou formar uma amostra de indivíduos com boa homogeneidade. Ou seja, o objetivo foi selecionar instituições que tivessem estruturas de remuneração, políticas de entrada e formação semelhantes de seus gerentes. As instituições financeiras estatais brasileiras possuem a característica singular de estarem vinculadas a legislações e a políticas institucionais semelhantes, geradas por um processo de isomorfismo institucional.

Outro critério de participação na pesquisa foi a exigência de que os respondentes possuíssem a certificação CPA-10, requerida pela Associação Brasileira das Entidades dos Mercados Financeiro e de Capitais (Anbima), certificação essa necessária para que um profissional das instituições participantes da associação possa desempenhar atividades de comercialização e distribuição de produtos de investimento com o público investidor. Essa exigência buscou um tratamento conservador para a pesquisa. Ou seja, ao se estipular uma amostra qualificada, com formação e experiência na área financeira, buscou-se evidenciar que o efeito manada pode ocorrer inclusive em profissionais com experiência, acesso à informação e formação adequada.

A aplicação do questionário foi realizada nos meses de abril e maio de 2015, por meio de visitas às agências bancárias da Caixa Econômica Federal, Banco Regional de Brasília e Banco do Brasil, todas localizadas no Distrito Federal. Os questionários foram entregues aos entrevistados, os quais aceitaram participar da pesquisa voluntariamente. Apesar da restrição geográfica da pesquisa, não foram encontradas razões para sugerir que a localidade da aplicação do questionário se constituísse um viés nas respostas da análise. Quanto à quantidade amostrada, foi de 80 respondentes no total, sendo 40 em questionários com a opinião do analista de investimentos e 40 em questionários sem qualquer opinião. Houve a preocupação de que essas amostras fossem grandes nos dois grupos para que se pudesse ter características assimptóticas e a possibilidade de se fazer uso de estatísticas paramétricas. Greene (2002) considera que amostras de tamanho a partir de 30 observações já podem ser consideradas amostras grandes. 
Como o efeito manada não é uma variável observável diretamente, torna-se necessário o uso de proxies para a sua mensuração (SANCHES, 2013). Assim, para testar a ocorrência de efeito manada, foram aplicados dois tipos de questionários a funcionários de três bancos públicos. Primeiramente, era apresentado um Balanço Patrimonial, uma Demonstração do Resultado do Exercício e uma Demonstração dos Fluxos de Caixa, em seguida, uma bateria com 10 questões divididas em três blocos. Havia dois tipos de questionários, e a única diferença entre eles era que um apresentava a opinião do analista com recomendação de compra das ações da empresa e no outro não havia qualquer opinião expressa. O objetivo da inserção dessa opinião em parte dos questionários era medir se os respondentes destes eram suscetíveis a seguir a opinião do analista. O primeiro bloco de questões se refere ao perfil do entrevistado, abrangendo perguntas a respeito do gênero, idade, nível de escolaridade, área de estudo e tempo de atuação no mercado financeiro. Já o segundo bloco é composto de três questões referentes ao desempenho da empresa; nessa parte era solicitado ao respondente que atribuísse uma nota de 0 a 10, sendo 0 correspondente a pior e 10, a melhor, para os índices de liquidez, endividamento e gestão da empresa. É importante mencionar que os índices foram calculados previamente e repassados aos respondentes, de forma a acelerar o processo de resposta. Os índices apresentados pela empresa foram de 1,25 e 0,5 para liquidez e endividamento, respectivamente. A nota para gestão era atribuída pelo respondente, sem qualquer indicador apresentado, cabendo a ele próprio arbitrar um valor. O terceiro bloco foi composto por duas questões objetivas, a primeira sobre a percepção do respondente em relação à eficiência da gestão, e a segunda sobre se o respondente compraria ações da empresa. As respostas dos questionários foram tabuladas e analisadas com a ajuda do software estatístico SPSS.

Quanto ao tratamento dos dados, primeiramente, foram elaboradas estatísticas descritivas para a idade, nível de escolaridade, gênero, perfil escolar e nível de experiência. Nos questionários, os gerentes pontuavam três indicadores (liquidez, endividamento e gestão) para testar se havia diferença entre as médias dos dois grupos (o com opinião e o sem opinião), e optou-se por um teste de médias em amostras independentes. Para isso, primeiramente, foi testado o ajustamento das variáveis por meio do teste Kolmogorov-Smirnov (Ks). Depois da execução do teste foi averiguado que as variáveis em estudo não eram normais, assim, optou-se por se fazer o teste de média não paramétrica. O teste não paramétrico comumente utilizado para variáveis independentes, como é o caso em estudo, é o Mann-Whitney, o qual teve a função de indicar se o fato de existir a opinião de um analista alteraria a forma de um gerente habilitado qualificar uma empresa. 
Por fim, buscou-se analisar a relação entre a opção de compra das ações e a opinião de um analista. Para tanto, foi feita uma investigação nas proporções das compras entre os grupos, com opinião e sem opinião do analista, em outras palavras, testá-las estatisticamente para medir se há ou não diferença significativa entre cada um dos grupos.

\section{ANÁLISE DE RESULTADO}

Quanto ao perfil da amostra, foi encontrado que 50 (62,5\%) respondentes são homens e apenas 30 (37,5\%) são mulheres. Ainda, a idade média dos participantes era de 37,15 anos, e o tempo médio de experiência era de 12,46 anos; também, 65\% dos respondentes cursaram cursos relacionados a negócios na faculdade, são eles: Contabilidade, Administração e Economia. O nível de escolaridade encontrado é apresentado a partir do Gráfico 1.

Gráfico 1 - Escolaridade dos respondentes

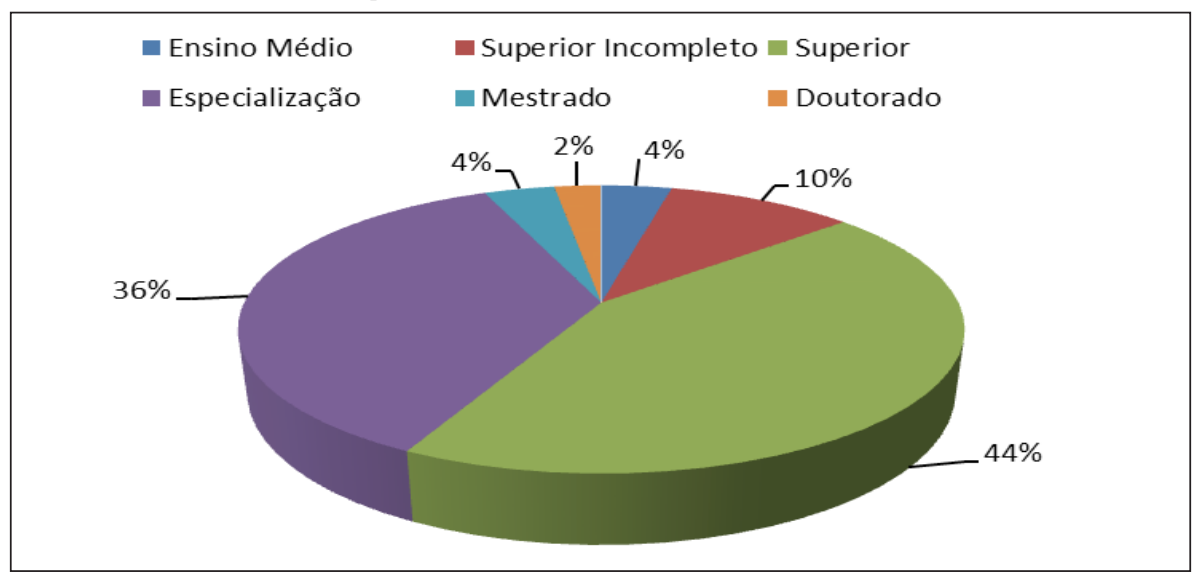

Fonte: os autores.

Por meio das Tabelas 1 e 2 são apresentados os valores das estatísticas das respostas para as variáveis liquidez, endividamento e gestão. Quando comparada a análise descritiva da amostra com opinião e da amostra sem opinião, nota-se haver uma diferença entre os grupos. Os questionários com opinião apresentam médias maiores, com valores de 6,78, 6,48 e 6,25 para os indicadores liquidez, endividamento e gestão, e de 5,85, 5,40 e 4,75, respectivamente, no grupo sem a opinião. Dessa forma, sugere-se que os gerentes que tinham em mãos o questionário com a opinião pontuaram a empresa de forma mais positiva. Quanto aos desvios padrões, foram 
achados os valores de 1,82, 2,03 e 4,90 para as variáveis liquidez, endividamento e gestão no grupo com a opinião do analista; já no grupo sem a opinião foram encontrados 2,38, 2,50 e 5,06, respectivamente. Esses valores sugerem, à primeira vista, um padrão de resposta mais homogêneo entre os respondentes que obtiveram a opinião de um analista durante as respostas. Como as médias foram maiores, sugere-se, também, uma tendência de atribuir valores maiores aos indicadores que qualificam em melhor nível a empresa em que há recomendação de compra.

Tabela 1 - Análise descritiva das variáveis com opinião do analista

\begin{tabular}{llll}
\hline Variáveis & Média & Mediana & Desvio padrão \\
\hline Liquidez & 6,78 & 7 & 1,82 \\
\hline Endividamento & 6,48 & 7 & 2,03 \\
\hline Gestão & 6,25 & 1 & 4,90 \\
\hline
\end{tabular}

Fonte: os autores.

Tabela 2 - Análise descritiva das variáveis sem opinião do analista

\begin{tabular}{llll}
\hline Variáveis & Média & Mediana & Desvio padrão \\
\hline Liquidez & 5,85 & 5 & 2,38 \\
\hline Endividamento & 5,40 & 5 & 2,50 \\
\hline Gestão & 4,75 & 0 & 5,06 \\
\hline
\end{tabular}

Fonte: os autores.

Para se verificar a possível normalidade das variáveis em estudo, foi realizado o teste de normalidade Kolmogorov-Smirnov (Ks), o qual considera como hipótese nula a normalidade e como hipótese alternativa a não normalidade. Foi verificada a não normalidade das variáveis liquidez, endividamento e gestão, visto que o p-valor do teste Ks para todas as variáveis não ultrapassou 0,001. Diante da não normalidade e da existência de um delineamento independente, para testar a diferença entre as médias, optou-se pela aplicação do teste não paramétrico Mann-Whitney, cujos resultados podem ser vistos na Tabela 3 .

Tabela 3 - Teste Mann-Whitney

\begin{tabular}{llll}
\hline Variáveis & Mann-Whitney & $\mathrm{Z}$ & Significância \\
\hline Liquidez & 641 & $-1,55$ & 0,121 \\
\hline Endividamento & 586 & $-2,09$ & 0,037 \\
\hline Gestão & 680 & $-1,34$ & 0,180 \\
\hline
\end{tabular}

Fonte: os autores. 
O resultado obtido confirma que a opinião do analista não interferiu na maneira de os participantes pontuarem o indicador contábil liquidez e de qualificarem a gestão. Já o endividamento apresentou diferença significativa entre as médias, visto que a amostra com recomendação do analista qualificou o endividamento como $20 \%$ melhor que a amostra sem a opinião.

Para testar se há influência da opinião do analista de mercado na opção de compra das ações da empresa, foi realizado teste nas proporções de compra dos dois grupos, com opinião e sem opinião, por meio do teste Qui-quadrado $\left(\mathcal{X}^{2}\right)$. A partir da Tabela 4 é possível visualizar que a proporção dos gerentes que optaram pela compra foi bastante superior no grupo em que havia a opinião favorável do analista.

Tabela 4 - Proporções obtidas

\begin{tabular}{llll}
\hline Variáveis & Com opinião do analista & Sem opinião do analista & Total \\
\hline Comprar ações & $27(67,5 \%)$ & $16(40 \%)$ & 43 \\
\hline Não comprar ações & $13(32,5 \%)$ & $24(60 \%)$ & 37 \\
\hline Total & $40(100 \%)$ & $40(100 \%)$ & 80 \\
\hline
\end{tabular}

Fonte: os autores.

Dos gerentes que fizeram a opção pela compra das ações, em 62,79\% havia opinião positiva dos analistas, e em 37,21\% não havia opinião alguma, gerando, assim, uma evidência para o relacionamento entre a opção pela compra e a opinião de analistas. Essa relação pode ter origem na limitação do autocontrole nas pessoas, visto que estas não são plenamente racionais, têm dificuldade diante do que desconhecem e correm risco porque não sabem que estão correndo risco (KAHNEMAN; TVERSKY, 1979; FERREIRA, 2011). Para verificar a validade desses achados, é aplicado o teste Qui-quadrado nas proporções achadas. Os resultados do teste podem ser vistos na Tabela 5.

Tabela 5 - Teste Qui-quadrado

\begin{tabular}{llll}
\hline Grupo & Estatística Qui-quadrado & Graus de Liberdade & P-valor \\
\hline Com Opinião & 4,9 & 1 & 0,027 \\
\hline Sem Opinião & 1,6 & 1 & 0,206 \\
\hline
\end{tabular}

Fonte: os autores.

No grupo com opinião do analista, no teste Qui-quadrado obteve-se estatística 4,9, com p-valor de 0,027 e grau de liberdade igual a 1 . Dessa forma, pode-se afirmar, com 95\% de certeza, que dentro do grupo com opinião do analista houve, em 
média, um maior número de gerentes optando pela compra das ações dessa empresa. Já no grupo em que não havia a opinião do analista, o teste Qui-quadrado apresentou uma estatística 1,6, com p-valor de 0,206, sugerindo, assim, que não houve uma diferença estatisticamente comprovada nas proporções entre as pessoas que optaram pela compra e as que não fizeram essa mesma opção. Esses resultados evidenciam uma forte relação entre a opinião de um analista de mercado e a opção de compra de um ativo, mesmo que os agentes tomadores de decisões sejam pessoas com alto nível de qualificação.

\section{CONSIDERAÇÕES FINAIS}

Nesta pesquisa teve-se como objetivo verificar se gerentes de bancos públicos que estão autorizados a recomendar investimentos sofreriam influência da opinião de um analista na decisão de compra das ações de uma empresa brasileira. Diferindo de outros trabalhos que testam apenas a existência de efeito manada no mercado financeiro, buscou-se realizar um estudo que justificasse a existência de efeito manada visto que diversos trabalhos já encontraram a presença de tal fenômeno no mercado de capitais. Para isso, foi analisada uma amostra com profissionais qualificados para atuarem em tal mercado.

A partir dos achados, conclui-se que a opinião do analista não causou interferência na maneira de os gerentes qualificarem a empresa quanto aos indicadores de liquidez, endividamento e gestão. No entanto, ao se analisarem as proporções de compra das ações nos dois grupos, com opinião e sem opinião de um analista de mercado, foram verificadas evidências que a opinião emitida por um analista de mercado, no presente caso, influenciou a decisão desses gerentes. Uma explicação para esse evento, segundo a Teoria dos Prospectos, é que o processo de decisão não é estritamente racional, dado que considera a influência das heurísticas de julgamento na alteração da forma de escolha racional.

Embora os gerentes tivessem certificação para recomendar investimentos, conhecimentos de contabilidade e finanças, além de uma melhor preparação para interpretar e avaliar a saúde financeira de uma empresa, foi observado que eles também estão susceptíveis a opiniões de terceiros. A partir do teste Qui-quadrado, foi verificada forte evidência da existência de uma possível relação entre a opção pela compra e a influência da opinião de um analista, indicando que profissionais qualificados também estão suscetíveis à ocorrência de efeito manada. O efeito manada ocorreria, nesse 
caminho, sob a influência de terceiros, dado que os agentes tendem a ter um comportamento de imitações, resultando em ações semelhantes.

Considerando-se que o tema carece de maiores informações quanto a associações entre comportamentos individuais e o efeito manada, sugere-se que outras pesquisas sejam feitas com mais investidores em potencial, também com estudantes de pós-graduação e professores de finanças, bem como agentes que atuam no mercado de capitais nacionais e internacionais. Relevante, também, seria a indicação de modelos estatísticos que verifiquem associações lineares e não lineares entre as decisões.

\section{REFERÊNCIAS}

ARAÚJO NETO, L. M.; FREIRE, F. S. Comportamento Manada: estudo aplicado em estudantes do curso de ciências contábeis. RIC - Revista de Informação Contábil, v. 7, n. 1, p. 23-34, jan./mar. 2013.

ARRUDA, P. B. Uma investigação sobre o efeito disposição. 2006. Dissertação (Mestrado em Engenharia de Produção)-Universidade Federal de Santa Catariana, Florianópolis, 2006.

BACHELIER, L. J. A. The Theory of Speculation. 1900. Tese (Doutorado em Matemática)-Universidade de Paris, 1900.

BARBEDO, C. H. da S.; SILVA, E. C. Finanças comportamentais: pessoas inteligentes também perdem dinheiro na bolsa de valores. São Paulo: Atlas, 2008.

BANERJEE, A. V. A Simple model of herd behavior. The Quarterly Journal of Economics, v. 107, i. 3, p. 797-817, 1992.

BIKHCHANDANI, S.; SHARMA, S. Herd behavior in financial markets. IMF Staff papers, v. 47, i. 3, p. 279-310, 2001.

CAMARGO, R. S.; CAJUEIRO, D. O. Minority game with local interactions due to the presence of herding behavior. Physics Letters A, v. 355, p. 280-284, 2006.

CAMPBELL, J. Y.; LO, A. W.; MACKINLAY, A. C. The econometrics of financial markets. New Jersey: Princeton University Press, 2012.

CARDOSO, R. L.; RICCIO, E. L.; LOPES, A. B. O processo decisório em um ambiente de informação contábil: um estudo usando a teoria dos prospectos. BASE Revista de Administração e Contabilidade da Unisinos, v. 5, n. 2, p. 85-95, 2008. 
CARMO, L. C. Finanças comportamentais: uma análise das diferenças de comportamento entre investidores institucionais e individuais. 2005. 91 p. Dissertação (Mestrado em Administração de Empresas)-Pontifícia Universidade Católica do Rio de Janeiro, Rio de Janeiro, 2005.

CHIANG, T. C.; ZHENG, D. An empirical analysis of herd behavior in global stock markets. Journal of Banking and Finance, i. 34, p. 1911-1921, 2010.

CONLISK, J. Why bounded rationality? Journal of Economic Literature, v. 34, p. 669-700, 1996.

CONT, R.; BOUCHAUD, J.-P. Herd behavior and aggregate fluctuations in financial markets. Macroeconomic Dynamics, v. 4, p. 170-196, 2000.

CHRISTIE, W. G; HUANG, R. D. Following the pied piper: do individual returns herd around the market? Financial Analysts Journal, v. 51, i. 31-37, 1999.

CUTLER, D. M.; POTERBA, J. M.; SUMMERS, L. H. What moves stock prices? Journal of Portfolio Management, p. 4-12, Spring 1989.

CUSINATO, R. T. Teoria da decisão sob incerteza e a hipótese da utilidade esperada: conceitos analíticos e paradoxos. 2003. Dissertação (Mestrado em Economia)-Universidade Federal do Rio Grande do Sul, Porto Alegre, 2003.

FAMA, E. Efficient capital markets: a review of theory and empirical work. Journal of Finance, v. 25, p. 383-417, 1970.

FARHI, M. Derivativos financeiros: hedge, especulação e arbitragem. Revista Economia e Sociedade, v. 13, p. 93-114, 1999.

FEEREIRA, V. R. M. A cabeça do investidor: conheça suas emoções para investir melhor. São Paulo: Évora, 2011.

GREENE, W. H. Econometric analysis. New York: Prentice Hall, 2002.

HALFELD, M.; TORRES, F. de F. L. Finanças comportamentais: aplicações no contexto brasileiro. Revista de Administração de Empresas, São Paulo, v. 41, n. 2, p. 64-71, 2001. 
JORDAN, D.; DILTZ, J. D. Day traders and the disposition effect. The Journal of Behavioral Finance, v. 5, i. 4, p. 192-200, 2004.

KAHNEMAN, D.; TVERSKY, A. Prospect judgment under uncertainty: heuristics and biases. Sciences, v. 185, p. 1124-1131, 1974.

KAHNEMAN, D.; TVERSKY, A. Prospect theory: an analysis of decision under risk. Econometrica, p. 263-291, Mar. 1979.

KEYNES, J. M. The general theory of employment, interest and money. London: Macmillan, 1936.

KIMURA, Herbert. Aspectos comportamentais associados às reações do mercado de Capitais. RAE Eletrônica, v. 2, n. 1, p. 1-14, 2003.

KUTCHUKIAN, E. O efeito manada nos fundos de investimento no Brasil: um teste em finanças comportamentais. 2010. Dissertação (Mestrado em Administração de Empresas)-Escola de Administração de Empresas de São Paulo, São Paulo, 2010.

KUTCHUKIAN, E.; EID JUNIOR, W.; DANA, S. O efeito manada nas captações de fundos de investimento no Brasil entre 2005 e 2009. In: ENCONTRO BRASILEIRO DE FINANÇAS, 10., 2010, São Paulo. Anais... São Paulo: Sociedade Brasileira de Finanças, 2010. v. 1.

LAKONISHOK, J.; SHLEIFER, A.; VISHNY, R. W. The impact of institutional trading on stock prices. Journal of Financial Economics, v. 32, i. 1, p. 23-43, ago. 1992.

LOBÃO, J.; SERRA, A. P. Herding behavior: evidence from portuguese mutual funds. Working paper, Mar. 2002.

LUX, T. Herd behaviour, bubbles and crashes. The Economic Journal, p. 881-896, 1995.

MARKOWITZ, H. Portfolio selection. The Journal of Finance, v. 7, i. 1, p. 77-91, 1952.

MATTAR, F. N. Pesquisa de marketing: metodologia, planejamento, execução e análise. 5. ed. São Paulo: Atlas, 1999. 
MOSCA, A. Finanças comportamentais: gerencie suas emoções e alcance sucesso nos investimentos. Rio de Janeiro: Elsevier, 2009.

ODA, A. L.; YOSHINAGA, C. E.; FAMÁ, R. Análise da sobre-reação de preços no mercado de ações brasileiro no período 1995-2003. In: SEMINÁRIO EM ADMINISTRAÇÃO, 8., 2005, São Paulo. Anais... São Paulo, 2005.

\section{REIDY, J.; DANCEY, C. P. Estatística sem matemática para psicologia usando} SPSS para Windows. [S.l.]: Artmed, 2006.

SAMUELSON, P. A. St. Petersburg paradoxes: defanged, dissected, and historically described. Journal of Economic Literature, v. 15, p. 24-55, 1977.

SANCHES, M. V. Comportamento de manada em direção ao índice de mercado: evidências no mercado brasileiro de ações. 2013. Dissertação (Mestrado em Administração de Empresas)-Universidade de São Paulo, São Paulo, 2013.

SCHARFSTEIN, D. S.; STEIN, J. C. Herd behavior and investment. The American Economic Review, v. 80, i. 3, p. 465-479, Jun. 1990.

SHILLER, R. J. Market volatility. Cambridge: MIT Press, 1989.

SIAS, R. Institutional Herding. Review of Financial Studies, v. 17, n. 1, 165-206, 2004.

SILVA, R. F. M. da et al. Finanças comportamentais: um estudo comparativo utilizando a teoria dos prospectos com alunos de graduação do curso de ciências contábeis. Revista Brasileira de Gestão de Negócios, v. 11, n. 33, p. 383-403, out./dez. 2009.

SIMON, H. A. Rationality as Process and as Product of Thought. American Economic Association, v. 68, i. 2, 1978.

SHLEIFER, A. Inefficient markets: an introduction to behavioral finance. Oxford: Oxford University Press, 2000.

TEH, L. L.; BONDT, W. F. M. Herding Behavior and Stock Returns: An Exploratory Investigation. Swiss Journal of Economics and Statistics, v. 133, p. 293-324, 1997. 
THALER, R.; BARBERIS, N. A survey of behavioral finance. In: CONSTANTINIDES, G.; HARRIS, M.; STULZ, R. (Ed.). Handbook of the Economics of Finance. New York: North-Holland, 2003.

TRUEMAN, B. Analyst forecasts and herding behavior. The Review of Financial Studies, v. 7, i. 1, p. 97-124, 1994.

TVEDE, L. The psychology of finance. [S.l.]: John Willey and Sons, 2000.

VARIAN, H. R. Microeconomia: princípios básicos. Rio de Janeiro: Campus, 2006.

YOSHINAGA, C. E. et al. Finanças comportamentais: uma introdução. REGE Revista de Gestão USP, v. 15, n. 3, p. 25-35, jul./set. 2008.

VON NEUMANN, J.; MORGENSTERN, O. Theory of games and economic behavior. New Jersey: Princeton University Press, 1944.

Como citar este artigo:

ABNT

ARAUJO NETO, Luiz Medeiros de et al. Efeito manada no mercado de capitais: um estudo com gerentes de bancos públicos do Distrito Federal. RACE, Revista de Administração, Contabilidade e Economia, Joaçaba: Ed. Unoesc, v. 15, n. 2, p. 601-620, maio/ago. 2016. Disponível em: <http://editora.unoesc.edu.br/index.php/ race $>$. Acesso em: dia/mês/ano.

APA

Medeiros de Araujo Neto, L., Serrano, A. L., Oliveira Neto, J. C. da C., Correia de Freitas, R. L. \& Sousa de Abreu, E. (2016) Competências gerenciais evidenciadas e desejadas dos integrantes do fórum de gestão de pessoas da rede federal de educação profissional, ciência e tecnológica. RACE, Revista de Administração, Contabilidade e Economia, 15(2), 601-620. Recuperado de http://editora.unoesc.edu.br/index.php/ race 
